\title{
ELECTRON DIFFRACTION IN SOME CUBICAL CRYSTALS*
}

\author{
By SUBODH KUMAR MAJUMDAR \\ (Reccived for publigation, September 19, 1951) \\ Plite XX
}

ABSTRACT. The spacings of a numbir of cubical crystals, obtained by metal shadowing in high vacuum, have been determinedin the electron microscope from the diffraction photographs. Except for AgIr, the value tally with those obtained from X-ray diffraction measurements. The diffraction photographs obtaincd are very much sharper than similar pictures obtained with metal foils by previous workers.

De Broglie's theory concerning the wave nature of beams of electrons rendered it possible for a stream of accelerated electrons to be used for determining the spacings of crystals. 'The experiments of Davisson and Germer $\left(r_{22} ;\right)$ first demonstrated the practical possibility of using clectron beams for producing diffraction patterns of crystals. Thomson (1929) and others used thin metallic foils for producing diffraction effects with high speed electrons $\left({ }_{5} \mathrm{KV}-60 \mathrm{KV}\right)$.

Although the main use of the electron microscope has been until now the production of electron micrographs, a number of workers have in recent years utilised the interference phenomenon of electrons for measuring the spacings of different crystals. As a matter of fact, the best way to carry out these experiments would be to make parallel observations with $X$-rays and electron beams under similar conditions. Beischer (r943) bas compared such results with fine crystalline and colloidal substances. In such comparisons, the wave-length of the electron beam was not calculated from theory, but with the help of aluminium oxide foil as the calibrating substance. Measurement of some other physical properties, such as conductivity, simultaneously with electron diffraction have been attempted by Hass (ro46) with silver and aluminium shadowed samples. Other workers such as Mahl (r942), Moliére (1940) and Möllenstedt (1944) have improved the technique of the measurements.

\section{F X PERIM N N TA L}

The experiments were performed at the Virusforschungsinstitut, Heidel. berg, with the kind permission of Prof. G. A. Kausche. The electron microscope was of the Borres-Ruska double magnification type made by

* This work forms a part of the investigation carried ont by the author at Virusforchungainstitut, Heidelberg/a Necker, Germany in 1950-5x. 
Siemens, Berlin. High voltages of $55 \mathrm{KV}$ and $70 \mathrm{KV}$ were used for acceleratiug the electrons in different cases. The objective aperture piece was made of platinum-gold with a diameter of $0.3 \mathrm{~mm}$. For diffraction experiments, the projective magnet piece was taken out and the diffracted beams photographed.

$\because \quad$ Thin deposits of metals like gold, silver and copper were made on saponin membrane placed on the aperture piece by shadowing in high vacuum. Pieces of the metal were placed inside a tungsten spiral held in position above the aperture piece within a bell jar evacuated to high vacuum and the thickness of the deposits was controlled by the time of flow, current strength and the angle of shadowing. For silver chloride and silver bromide, the shadowing was done with silver in presence of chlorine and bromine vapour respectively within the bell jar at equally low pressure.

$\therefore$ The distance between the objective and the plate was $57.5 \mathrm{~cm}$. The plates" were developed and the distances between the circles were measured.: under a travelling microscope.

Table I gives particulars about the high voltage used and the current strength in the different cases and Plate $\mathrm{XX}$ illustretes the diffraction patterns obtained.

TABLE I

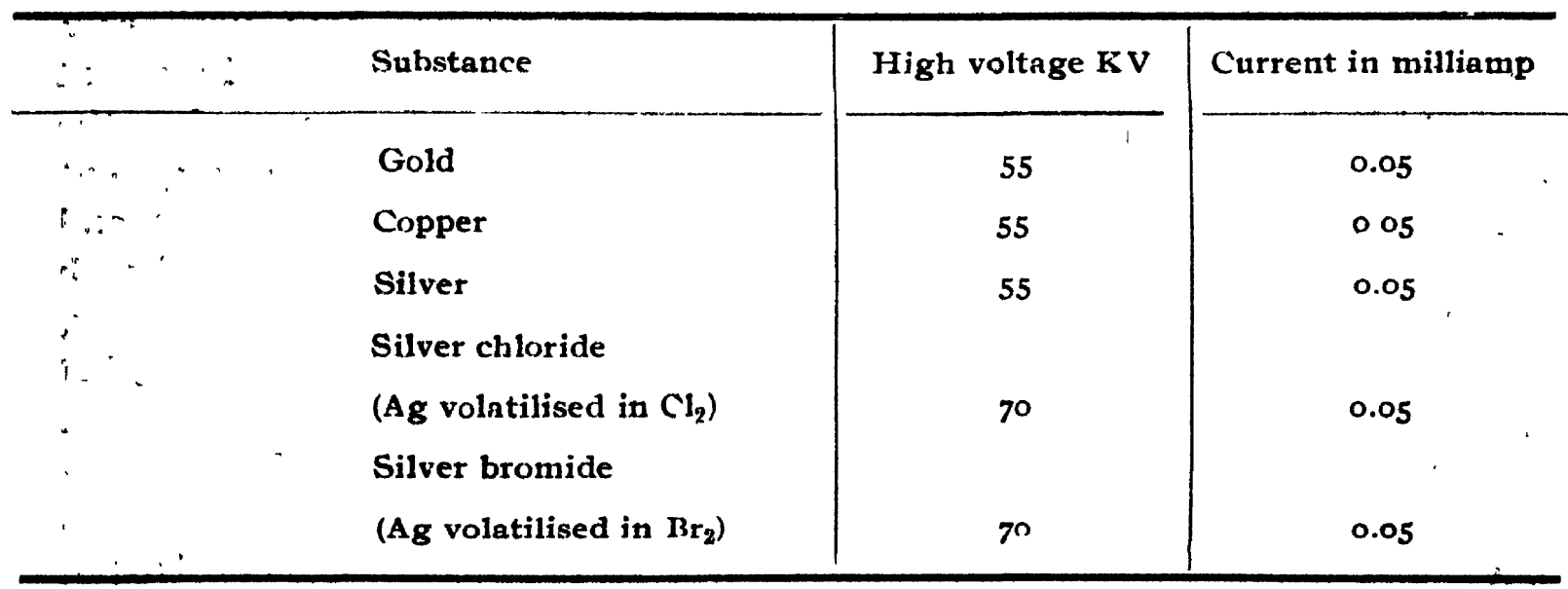

The spacings were calculated in the following manner. If the incident beam after reflection from a particular plane $(h, k, l)$ makes a cone of half angle $\theta / 2$ (figure $I$ ), then $r / h=\tan \theta / 2$, where $h$ is the distance of the objective from the plate and $r$, the radius of the particular circle.

Then $\theta / 2=\tan ^{-1}(r / h)$ and hence $\sin \theta / 2$ can be calculated for different values of $r$. By the method of trial and error, the constant value of sin $a+2$, using different values of $n\left(=\sqrt{h^{2}+k^{2}+l^{2}}\right)$ are obtained, correspond- 


\section{Electron Diffraction in some Cubical Crystals}

ing to each circle. If this constant value is $k$, then spacing $a_{0}$ is given by

$$
a_{0}=-\frac{\lambda}{2 \frac{\sin \theta / 2}{\sqrt{h^{2}+k^{2}+l^{2}}}}=\frac{\lambda}{2 K}
$$

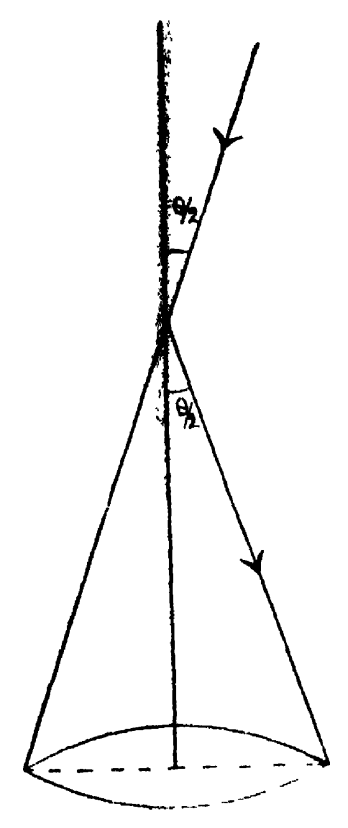

FiG. I

' 1 'he value of $\lambda$ is calculated from the equation

$$
\lambda=\frac{h}{\sqrt{2 m_{0} \cdot e \cdot U\left(I+\frac{e . U}{2 m_{0} c^{2}}\right)}},
$$

where $\quad h=$ Planck's constant $=6.626 \times 10^{-27} \mathrm{erg} / \mathrm{sec}$;

$m_{o}=$ rest mass of the electron $=9.108 \times 10^{-28} \mathrm{gm}$. ,

$e=$ charge of the electron $=4.803 \times 10^{-10} \mathrm{C}$. G. S. units ;

$c=$ velocity of light $=3.00 \times 10^{10} \mathrm{~cm} / \mathrm{sec}$;

$U=\operatorname{applied}$ E. M. F. (C. G. S. units).

The values of $\lambda$ for $70 \mathrm{KV}$ and $55 \mathrm{KV}$, the two accelerating voltages, are found to be

$\begin{array}{lc}\text { Voltage } & \lambda \\ 70 \mathrm{KV} & 0.04485 \AA \\ 55 & 0.05095\end{array}$

Tables II-VI give the values of $x$, the diameters of the ripgs in $\mathrm{cm}, \theta / 2$, $\sin \theta / 2$ and $K$, the constant for the particular plane of reflection. 
TABL,E II

Gold ( $1034 / 43)$

Voltage used $=55 \mathrm{KV} \pm 215$ volts. $.05095 \AA$

\begin{tabular}{|c|c|c|c|c|}
\hline Nature & $s$ & $\mathbf{w}$ & $\mathbf{w}$ & $\mathbf{w}$ \\
\hline$x(\mathrm{~cm}.) \ldots$ & 2.595 & 3.015 & 4320 & $5 . \times 10$ \\
\hline$\theta / 2 \quad \ldots$ & $x^{\circ} 17^{\prime}$ & $x^{\circ} 30^{\prime}$ & $2^{\circ} 9^{\prime}$ & $2^{\circ} 32^{\prime}$ \\
\hline $\sin \theta / 2 \ldots$ & .0112 & .0231 & .0187 & .0221 \\
\hline $\boldsymbol{K} \quad \ldots$ & .00646 & .00650 & $.0066 \mathrm{I}$ & .00663 \\
\hline
\end{tabular}

Mean value of $K=.00655$.

Hence

$$
a_{o}=\frac{.05-2 v}{2 \times .00655} \AA=3.90 \AA .
$$

Standard value for $\mathrm{Au}=4.07 \AA$.

TABI, III

Copper (1042/46)

Voltage used $=55 \mathrm{KV} \pm 215$ volts.

$\lambda=.0509 .5 . \AA$.

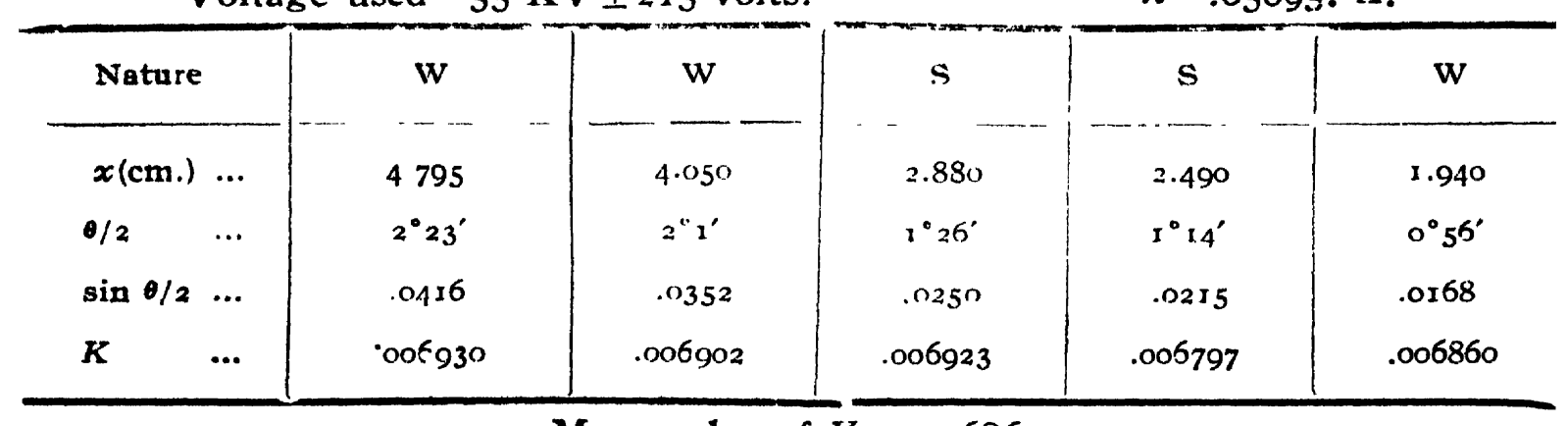

Mean value of $K=.00686$.

Hence

$$
a_{0}=\frac{.005095}{2 \times .00686} \AA=3.71 \AA \text {. }
$$

Standard value for $\mathrm{Cu}=3.60 \AA$.

TABI,E IV

Silver chloride (silver volatilised in chlorine). (1470;46).

\begin{tabular}{|c|c|c|c|c|c|c|c|c|}
\hline Nature & & $\mathbf{v} \cdot \mathbf{w}$ & $\mathbf{w}$ & $\mathbf{w}$ & $\mathbf{v} \cdot \mathbf{w}$ & V.s & V.s & $\mathbf{s}$ \\
\hline$x(\mathrm{~cm})$. & ... & 4.945 & $4.37^{85}$ & 3.392 & 3.244 & 2.768 & I.959 & 1.695 \\
\hline $0 / 2$ & $\cdots$ & $2^{\circ} 28^{\prime}$ & $2^{\circ} 1 I^{\prime}$ & $x^{\circ} 4 x^{\circ}$ & $x^{\circ} 37^{\prime}$ & $1^{\circ} 23^{\circ}$ & $0^{\circ} 50^{\prime}$ & $0^{\circ} 5^{8}$ \\
\hline $\sin \theta / 2$ & $\cdots$ & .0430 & .0381 & .0294 & $: 0282$ & $.024 I$ & 0169 & .0146 \\
\hline $\mathbf{K}$ & $\ldots$ & $.04 \pi 0 x$ & $.004 I_{3}$ & .00415 & .00426 & .00416 & .004 to & .004037 \\
\hline
\end{tabular}

Voltage used $=70 \mathrm{KV} \pm 215$ volts. $\quad \lambda=.0448$

Mean value of $K=.00412$. 


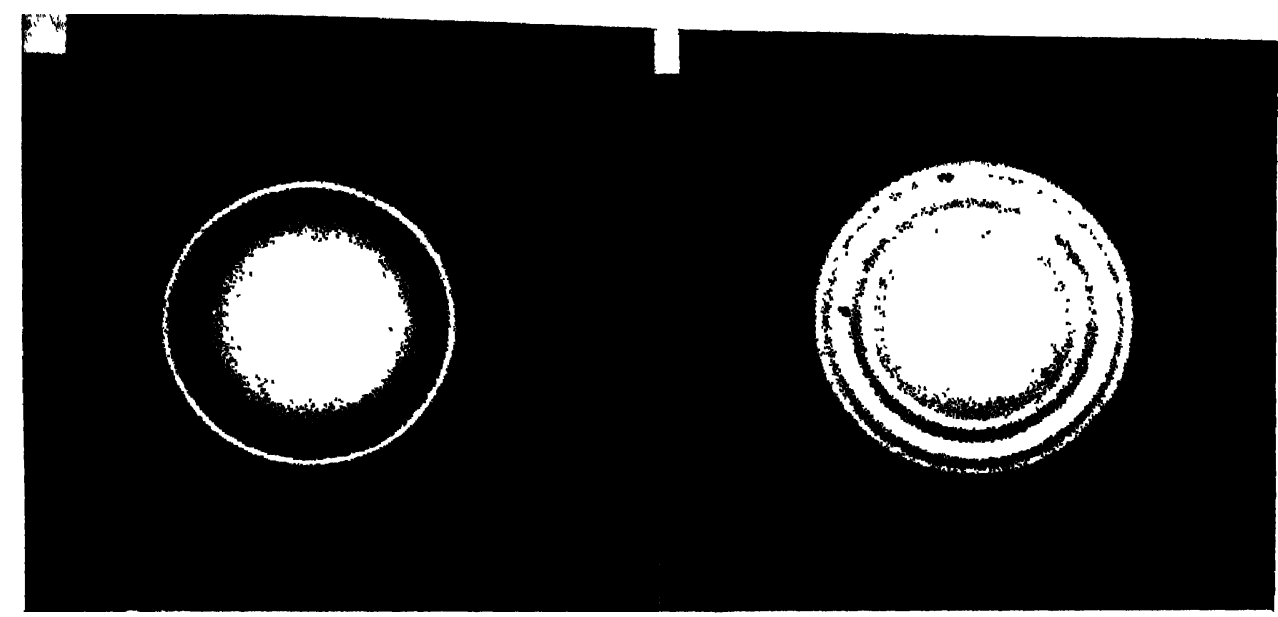

(a)

(b)

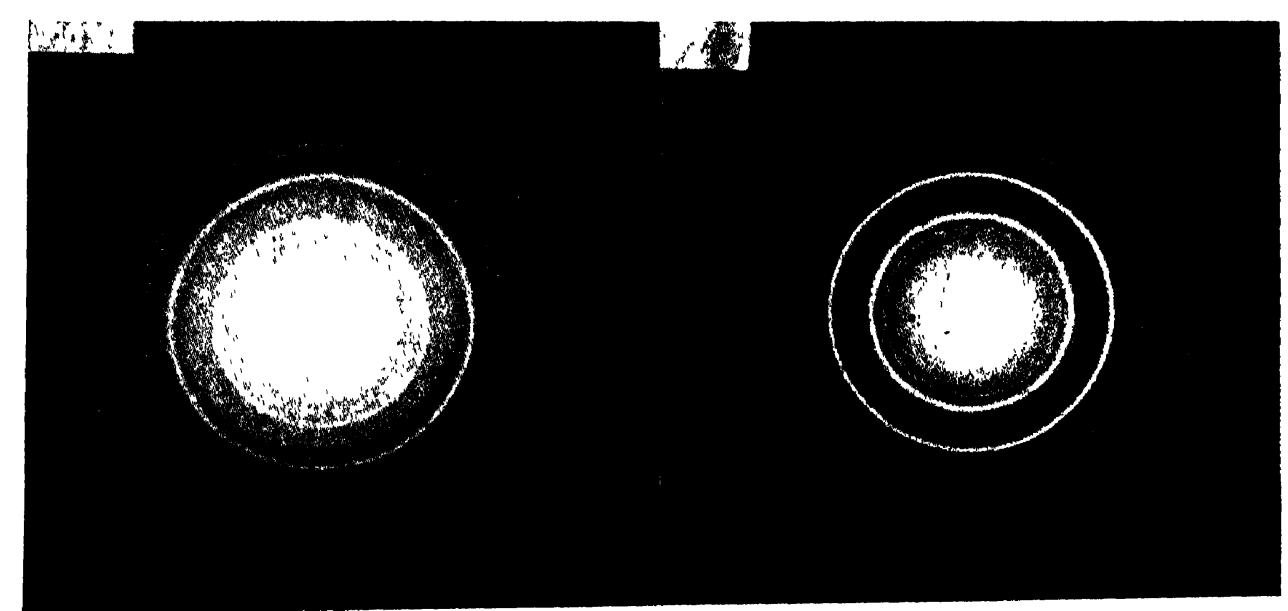

(c)

(d)

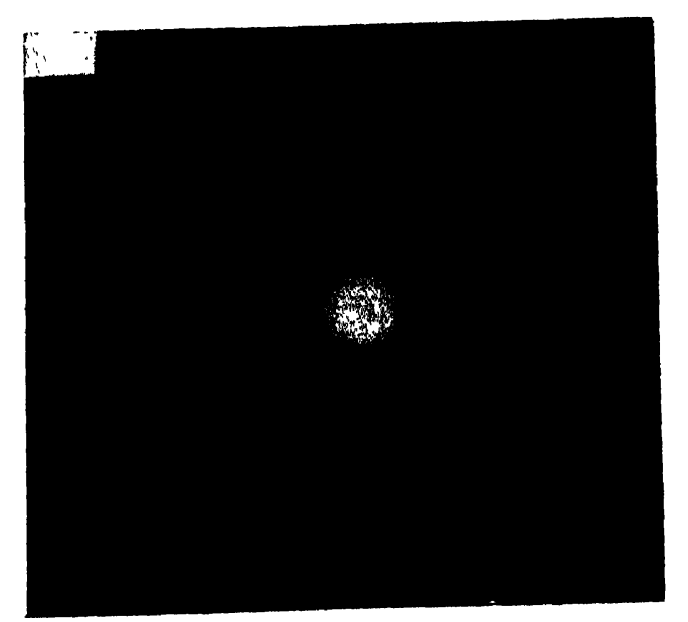

(e)

Fig. (a) Gold

(b) Copper

Electron diffraction patterns

Fig. (c) Silver chloride

Fig. (e) Silver

(d) Silver bromide 



\section{Electron Diffraction in some Cubical Crystals}

Fience

$$
a_{0}=-\frac{.004 .18}{2 \times .00412} \AA=5.44 \AA
$$

Standard value for $\mathrm{AgCl}=5.54 \AA$.

\section{TABGE $\mathrm{V}$}

Silver bromide (silver volatiksed in bromine'. (1474/4 $)$ ).

Voltage used $=70 \mathrm{KV} \pm 25_{5}$ volt $\quad \lambda=.0448 \AA$

\begin{tabular}{|c|c|c|c|c|c|c|}
\hline Nature & $\mathbf{w}$ & $\mathbf{S}$ & $v s$ & $\mathbf{s}$ & $\mathbf{w}$ & $\mathbf{w}$ \\
\hline$x(\mathrm{~cm}) \ldots$ & $x \cdot 597$ & 1.860 & 26 & $3.25 x$ & 4.215 & 4.627 \\
\hline$\theta / 2 \quad \ldots$ & $0^{\circ} 47^{\prime}$ & $0^{\circ} 55^{\prime}$ & $1^{\circ}$ & $1^{\circ} 37^{\prime}$ & $2^{\circ} 16^{\circ}$ & $2^{\circ} 18^{\circ}$ \\
\hline $\sin \theta / 2 \ldots$ & .01388 & $.016 r$ & .023 & .0282 & .0366 & .0401 \\
\hline$\ldots$ & .00462 & .00467 & .00468 & .00470 & .00463 & .00466 \\
\hline
\end{tabular}

Nean value of $K=.00466$

Hence

$$
a_{0}=\underset{2 \times .00466}{.0448} . \AA=4.82 \AA .
$$

Standard value of $\mathrm{AgBr}=5.75 \AA$.

TABI,E VI

Silver (ro46/46)

Voltage used $=55 \mathrm{KV} \pm 215$ volts.

$\lambda=.05095 \AA$.

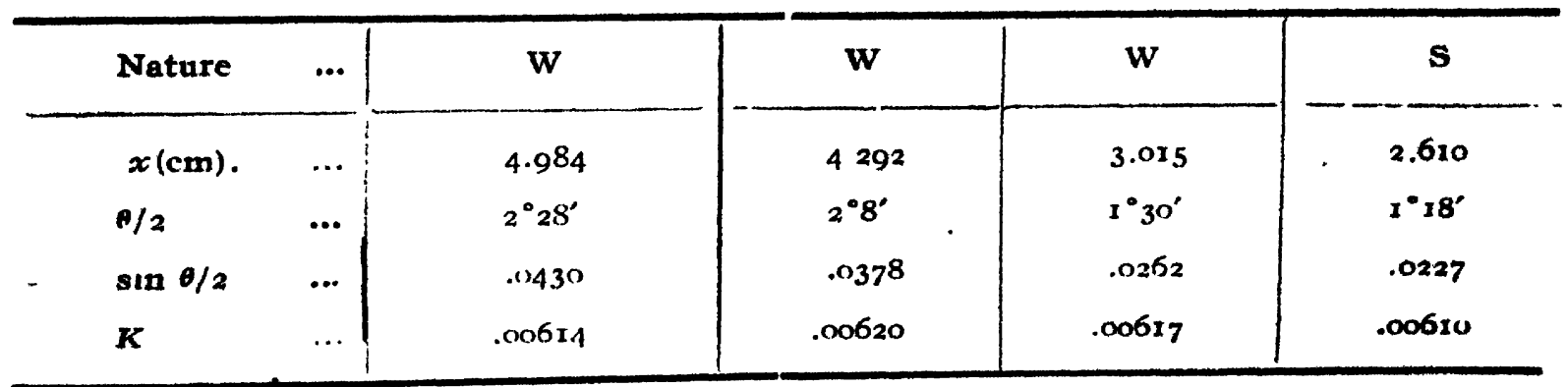

Mean value of $K=.00615$.

Hence

$$
a_{0}=\frac{.05095}{2 \times .00615} \AA=4.14 \AA \text {. }
$$

Standard value for $\mathrm{Ag}=4.08 \AA$.

It would thus appear that except for $\mathrm{A}_{8} \mathrm{Br}$, the values obtained from electron diffraction experiments agree fairly well with those from X-ray difraction experiments, bearing in mind the error involved, in maintaining a constant primary current and in the calculation of wavelengths of electron

$$
4-1778 P-11
$$


beams. The photographs of the diffraction rings are also much sharper than those previously obtained by other workers.

The discrepancy found in the case of $\mathrm{AgBr}$ may be attributed to either of the causes referred to above or to ineffective bromination in the shadowing apparatus. The value obtained $(4.812 \AA)$ is too small for $\mathrm{AgBr}$ and too large for silver $(4.08 \AA$ ). It is also not due to accidental falling off of tungsten particles (3.15 $\AA$ ) from the electron gun, as sometimes happens.

Interesting results have heen found with $\mathrm{NaCl}$ and $\mathrm{KCl}$ solutions, evaporated in high vacuun within the micoroscone. In these cases, in addition to the usual circles, number of spots have been noticed. These will form the subject of a later communication.

\section{ACKNOWI. FDG MENTS}

The author's best thanks are due to the (iovernment of West Bengal, for award of study leave, which made his stay in Germany possible, to Prof. G. A. Kasusche for kindly allowing him to work in his institute and to Dr. Haardick and Irrau Amy Engel for taking the diffraction photographs.

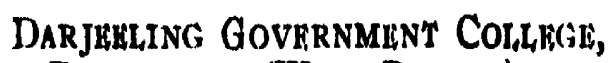
DARJRELING (WHST BTNGAL)

\section{RFF E R I N CFS}

Davisson and Germer, 19?7, Phys. Rev., 30, 705.

Thomson, G. P., ig29, Proc. Roy. Soc., A, 117, 600:A, 126, 352.

Beischer, 1943, Zeit. f. Flcktrochem., 49, 463.

Mollenstedt, 1946, Optik Part II.

Hass, 1946, Optik, I'art I.

Mahl, 1942, Naturwiss., 30, 208.

Moliese, 1940, 2cit. f. Elektrochcm., 36, 514.

Mollenstept, 1944, Ber. Phys. Inst. Danzig. 